\title{
Mockup Didactic Set for Students Development in Automotive Electronic
}

\author{
http://dx.doi.org/10.3991/ijep.v3iS3.2776 \\ F. S. Albaladejo ${ }^{1}$, A. T. de Carvalho ${ }^{1}$, C. A. Morioka ${ }^{1}$, F. Leonardi ${ }^{2}$, F. Delatore ${ }^{1,3}$ \\ ${ }^{1}$ FATEC Santo Andre, Santo Andre/SP, Brazil \\ ${ }^{2}$ Centro Universitario da FEI, Sao Bernardo do Campo/SP, Brazil \\ ${ }^{3}$ Universidade Anhanguera/UNIABC, Santo Andre/SP, Brazil
}

\begin{abstract}
The automotive engineering education area, specifically on internal combustion engine, requires the use of suitable systems, capable to simulate, test and obtain specifics data from its operation. Automotive engines are so complex due to it is a mix of engineering subjects, so, a mockup was created to help its study. The mockup is an exactly the same engine that equips a vehicle, but assembled in a mechanical base, equipped with all the necessary components for running it up. The objective of this work is to develop a mockup with a suitable Electronic Control Unit (ECU) board, in order to obtain the sensors/actuators signals from the engine and control some important engine functions by using an external ECU, so that the students may test their own strategies, compare with the original ECU.
\end{abstract}

Index Terms-automotive, didatic set, engine, mockup, ECU.

\section{INTRODUCTION}

The automotive electronic growth in the 80's was promoted by the government environment exigencies on the emissions laws of the exhaust gases. The automotive companies found in the electronic area an alternative to accomplish it [1]. Some of them introduced different conception of engine control on their cars. Firstly, they used an electro-mechanical injection, but this solution has been shown inefficient. The electronic carburetor was also created, but it was replaced quickly by the throttle body injection (TBI) in the 70's [2]. The TBI has become inept to achieve the engine emissions expected and with the microprocessor's growing of the 80 's, the single point electronic fuel injection arrived and with it, a lot of sensor and actuators i.e., injector nozzle, stepper motor to control the engine idle, MAF (Mass Air Flow), oxygen and others [5].

With all the engine modifications, the vehicles became more efficient and the automotive industry seeing these results, they started to invest more in technology, bringing new technologies i.e., communication's architectures (CAN, LIN, Flex ray), replacement of the single point by the multipoint injection, cruise control, airbag, anti-lock breaking system that turned the vehicle into a complex system [2].

The development of all this electronics stuffs in the automotive area is growing so fast nowadays. For the professionals that works on this area, it is extremely important the training and study on didactic platforms so requiring they behave as close as possible to the real systems. Automobile complexity made the industries change the development and training strategies, creating new methods to do it. One of these methods is the use of a real engine that is normally assembled in a mechanical support allowing developers to test the engine more efficiently, besides helping on the worker's training [4]. Mockups are commonly used in automotive companies to training the professionals that act in technical sales field and on the vehicles repairing. The mockup describes in this paper focus on training.

In this scenario, this paper presents the development of a didactic set to help the instructors to improve the automotive engineer student's skills, preparing them for a better understanding of the automotive subjects, manly on the engine management area. The didactic set is focused on engine management and the learning methodology was separated in three phases. The first phase, the students understand how the engine works, mainly the mechanical parts and principles. On the second phase, the focus is to present how the engine is controlled, including all the sensors and actuators. At last, the third phase is to prepare the students to develop an engine control system by using their own hardware and software.

\section{CARACHTERISTICS OF THE DidATIC SET}

In this section it will be discussing how the didactic set was developed, assembled, its requirements and the components used on this didactic set, divided on three parts: Mechanical Assembly, Intersecting and Hardware.

\section{A. Mechanical Assembly}

Identifying the instructor's and the student's deficits (lack of knowledge) were considered the first step on the didactic set development. The instructor's has a mission to graduate students with suitable knowledge that will be able to attend the needs of the industries. To identify the student's needs, a research with them was done and, for surprise, for the most of them, the first contact with engines and others automotive components occurred on the university classes, without any previous experience to help the teacher constructing a base of knowledge. These were the start up to define the requirements necessary to assemble the didactic set.

The General Motors Company donate to the university, a 1.8L engine flex fuel technology (Fig. 1), where is possible to use Gasoline (E0, E25) or Ethanol (E100) or the combination in any proportion of both fuels. The dimensions of this structure is approximately $1.50 \mathrm{~m}$ (length), $1 \mathrm{~m}$ (height) an $0.80 \mathrm{~m}$ (width), with rubber cushions and an empty gearbox on the engine's fixation in order to avoid futures fatigue's problems due the vibration of the set. 
Extra devices where attached on it to turn the engine operational (i.e. radiator, dashboard, ignition starter system, immobilizer, gas pedal, alternator, battery, coolant expansion tank, cold start system, starter motor, fuel pump, air filter and the ECU (electronic management unit)), allowing to run it and obtaining the final structure developed (Fig. 2).

\section{B. The Original ECU Intersecting Board}

As a second part, an intersecting system of the original ECU signals was implemented and integrated into the mockup structure. This interface is connected to the engine ECU providing an output/input pin for the engine sensors/actuators. This connection is controlled by means of a switch installed on the intersection panel (Fig. 3).

This interface was assembled in two circuit boards and a switch allows turning on/off any sensor/actuator of the engine, simulating a fault on it. The intersecting board also permits identifying the strategies adopted by the ECU to control the engine in each different operation mode: start up, warm up, idle speed, acceleration, deceleration and full load, acquiring the signals with a oscilloscope.

\section{The "Home Made" ECU}

The third phase of the methodology is focused on the study of the strategies adopted by the original ECU to control the engine. To help this, an ECU was developed on our labs, equipped with suitable electronics circuits and three microcontrollers where the students may record their own control software (Fig. 4), named as FATEC Santo Andre ECU.

This board is a didactic development platform where the student may apply all the knowledge acquired in order to improve some characteristic of the engine, i.e., control the throttle body, the injection map, and the ignition map. It is equipped with suitable electronics circuits that modify adequately the engine sensor's signals. There are also three microcontrollers where the students may code their own control software and some output pins that are linked with electronic power circuits, to act easily in some engine actuators, i.e., ignition coil, and injector valve.

The ECU was constructed in a circuit board and it is important to know what was established in the beginning of the project that the hardware would grow during the entire project, adding in each steps new functions and better devices thus increasing the processing power of the microcontrollers, the number of devices control and the introduction of some diagnostics devices.

This board was splited in three basics blocks: the Management, the Synchronism and the Diagnostic or Communication block (Fig. 5).

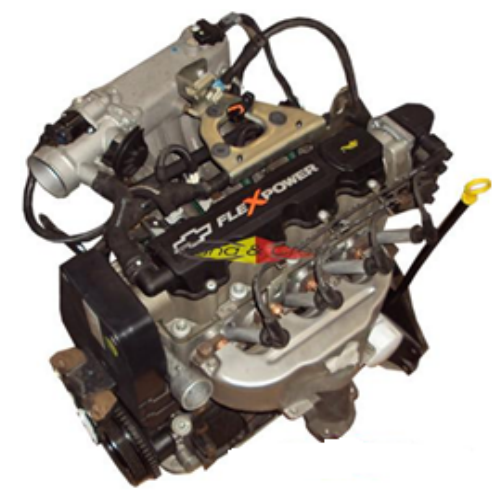

Figure 1. 1.8L Flex Fuel General Motors engine.

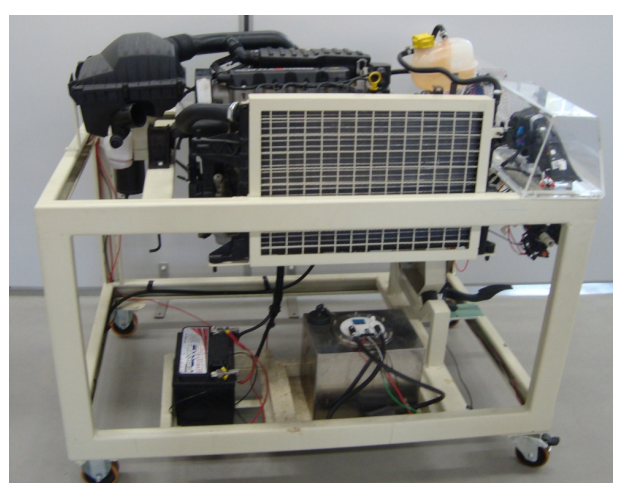

Figure 2. Overview of the mockup didatic set.

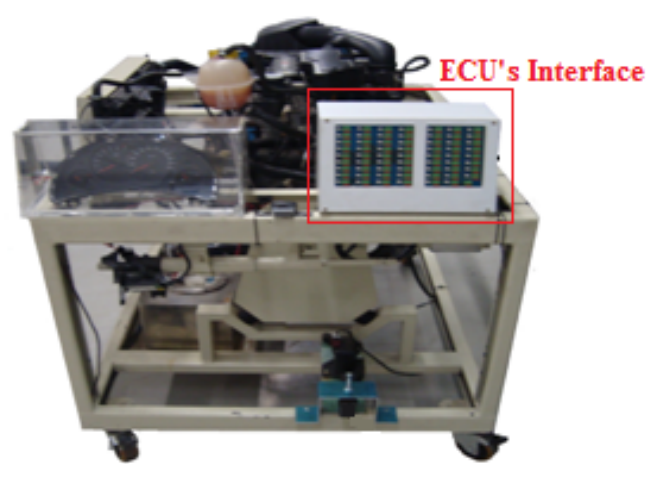

Figure 3. The original ECU intersecting board.

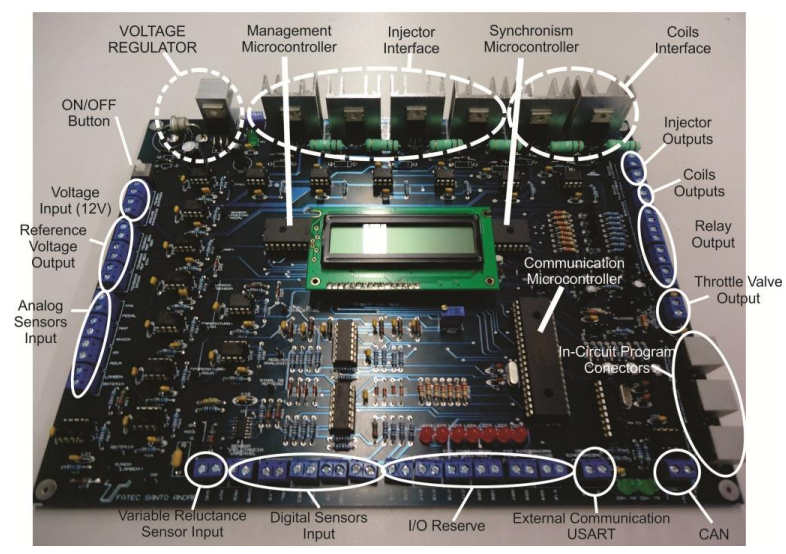

Figure 4. The FATEC Santo Andre ECU board.

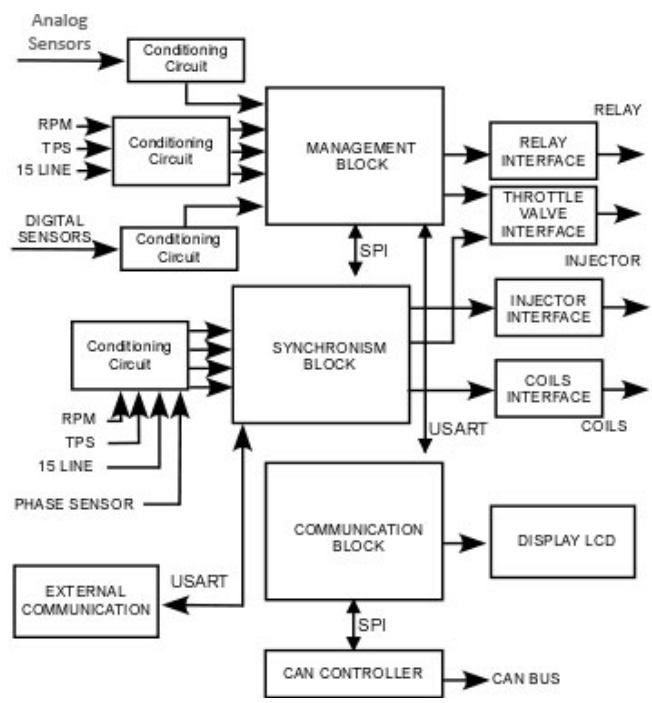

Figure 5. The "home made" ECU block diagram. 
The management block is responsible to receive the sensors signals, identify the engine operation mode and determine the suitable parameters to control the actuators, as the injectors valve and ignition coils. These parameters are after transferred to the synchronism block through a SPI (Serial Peripheral Interface) communication bus. This last block still controls the relays (main, fuel pump, starter) and the throttle body. The synchronism block creates all the control pulses to control the engine. Basically, it receives the parameters from the management block and must act over the injector valves and over the ignition coil on the exact moment to obtain the engine best performance.

The communication block collects the information by the engine CAN (Controller Area Network) network in order to characterize some fault on the engine, showing it on the LCD display. The intention of having an exclusive module to do this task, is to turn more simple and easy the teaching to the students the conception of the on board diagnosis system.

The microcontroller used on the ECU was the PIC $18 \mathrm{~F} 452$ with $32 \mathrm{~K}$ program memory. The microcontroller clock's operates on $20 \mathrm{MHz}$ without any problems or faults.

The extra electronic circuits present on the ECU is: voltage regulator, analogues and digitals conditioning circuits, adaptive reluctance sensor amplifier and interface power circuits for injector valves, ignition coils, relays and throttle body control.

The voltage regulator used to keep the voltage about 5 Volts was the LM2596, supplying the microcontrollers, all the conditioning circuits and the throttle body interface. The analogue conditioning circuits use two operational amplifiers, one in a voltage follower configuration and the other in an integrator configuration (Fig. 6).

The digital conditioning circuit (Fig. 7) uses just one operational amplifier in a differential input configuration, where the output signal was set to $5 \mathrm{~V}$ when the positive input signal it is above $2.5 \mathrm{~V}$. The diode on the input line is presented to limit the maximum output voltage as $5.7 \mathrm{~V}$.

For the reluctance sensor conditioning (engine rotation sensor) it was used the Texas Instruments IC LM1815.

Some electronic power circuits needed to be developed to perform a suitable interface between the microcontroller outputs and the engine actuators. An example, the Freescale IC MC33926 was used to control of throttle body motor. There are also two more circuits used to control the injector valves (Fig. 8) and the ignition coils (Fig. 9), combining the Texas Instruments IC LM1949 and NPN power Darlington transistors. The Proteus software was used to develop all the integrated circuits and circuit boards.

\section{RESUlTS AND Discussions}

Some results have been already observed on the students learning process in the end of some subjects that provides improvements in some undergraduate and master conclusion projects besides providing a better engagement of the students with the entire course. So hereafter it will be described some developed software by students.

\section{A. Developed Software}

By using the FATEC Santo Andre ECU, the students develop the engine control software during the Microcontroller classes. Firstly, the software's are tested

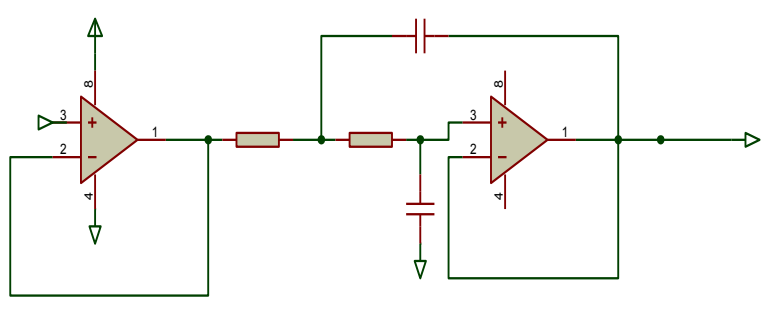

Figure 6. The analogue conditioning circuit.

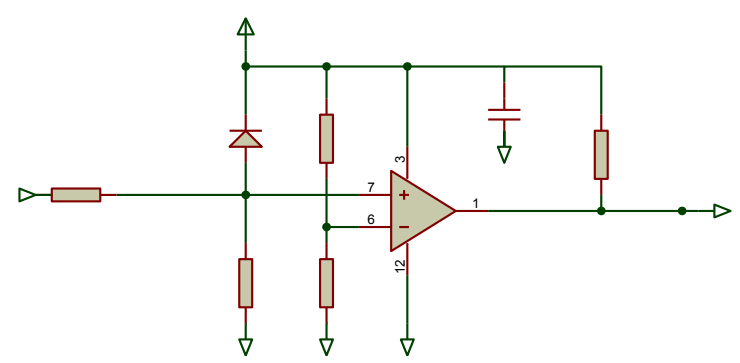

Figure 7. The digital conditioning circuit.

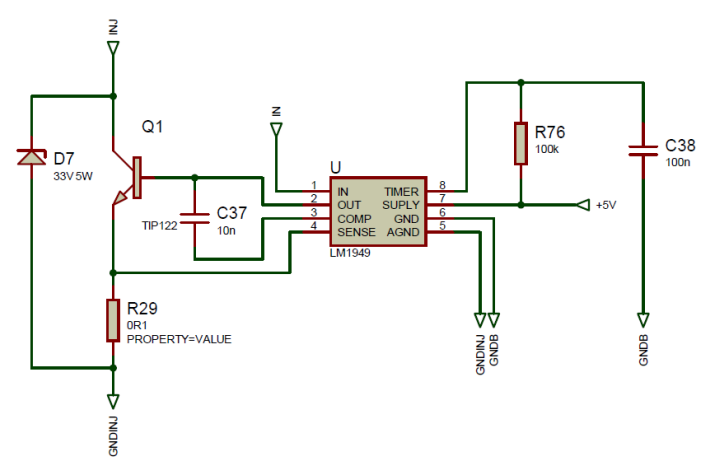

Figure 8. Interface circuit to the injector valves.

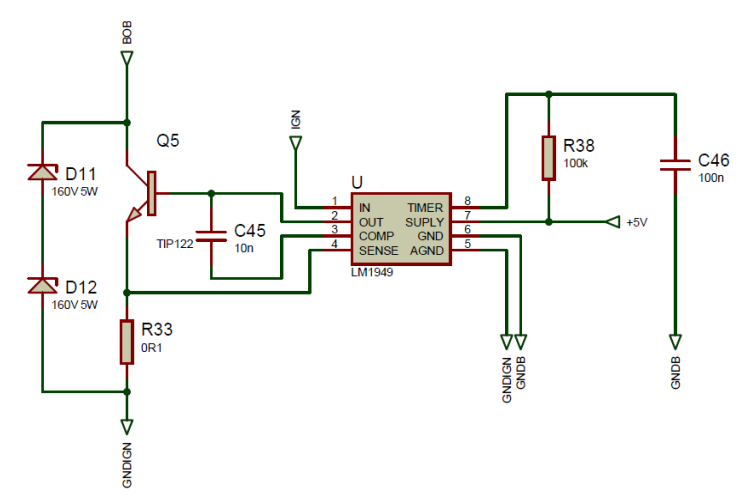

Figure 9. Interface circuit to the ignition coils.

in exclusives didactic sets as showed at Silva et al, 2012 [8]. After these preliminaries tests, the students are able to use the didactic set to test their own software's.

Generally, the students are organized in some groups where each one is responsible to control some engine actuator or to monitor some sensors in order to calculate some parameters. There are two examples of software developed by students describes above, represented in flowcharts.

The first software is developed by the students in order to manage the engine in the starter and idle speed operation. The strategy adopted to do this control was firstly monitoring the state of the commuter ignition (Fig. $10)$. 
On this preliminary software, basics configuration is be performed to configure the microcontroller ports in order to turn on/off the fuel pump (to pressurize the fuel gallery), reading some sensor signals and calculate the parameters necessary to start the engine. At last, its necessary to implement basics adjusts on the throttle body.

If someone put the key into the starter position the software enter into a routine called Key on Engine on (Fig. 11 ). On this routine, the fuel pump is turned on again and while the engine rotation keep below 400RPM, the system check the state of the key (if it turned it off, the program will restart) and act into the injector valve with a full group strategy (all injectors valves will be turned on, no matter of the camshaft angle ).

When the engine revolutions is above than 400RPM, the system remains in a while loop updating some parameters and controlling the throttle body position to guaranteed a perfect engine idle speed operation.

The third software developed is focused on receive some parameter from management block via SPI communication bus and control the time to act on the injector valves and ignition coils. Basically this software monitors the reluctance sensor to find out the crankshaft position angle. First, the microcontroller's hardware is initialized and the variables are declared. After that, the software identifies the discontinuity of the crankshaft position angle sensor, beginning a loop of injection and ignition control (Fig 12).

This control always has to be synchronized, as a function of the engine revolution, the parameter to act on each control system changes. After the $34^{\text {th }}$ tooth, all the parameters coming from management system are uploaded into the software, allowing a better performance in all engine operations. The parameters that are uploaded in the synchronism software are: injection and coil loading time and the exact moment for shooting the ignition and injection pulses.

\section{CONCLUSION}

This didactic set allows the students to have hands on experience with an engine, which for most of them, are their first contact. It permits to the instructor during his classes to create and construct a base of knowledge to a better understanding of how engines work and why all the electronic stuff are necessary for a superior engine control. The hardware combined with the FATEC Santo Andre ECU and the intersection board, gives to the instructor an import tool where the engine input/output signals could be easily linked.

By means of the switch installed on intersection board, is possible to compare the students control strategies with the original ECU strategies. Another important value is that this didactic set can be assembled with an estimated investment as low of approximately U\$ 10,000.00.

As mentioned, Mockups are commonly used in automotive companies to training the professionals that act in technical sales field. So, the mockup described in this paper has been an important equipment used to training and improve the students' skills on engine management area.

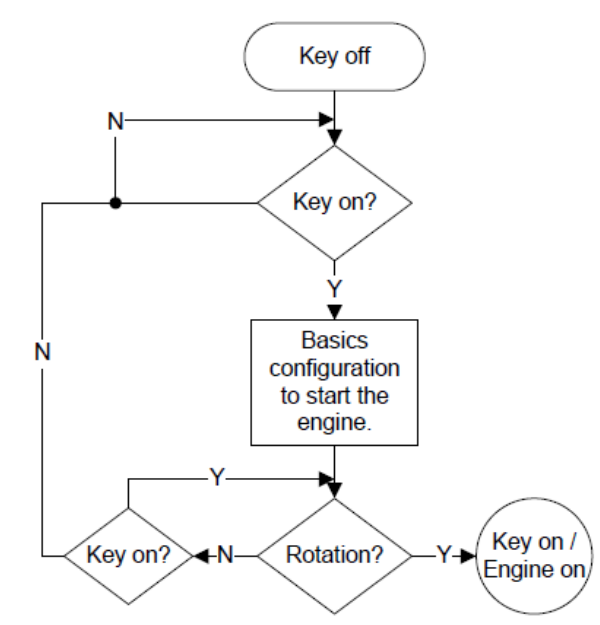

Figure 10. First software developed (Management 1).

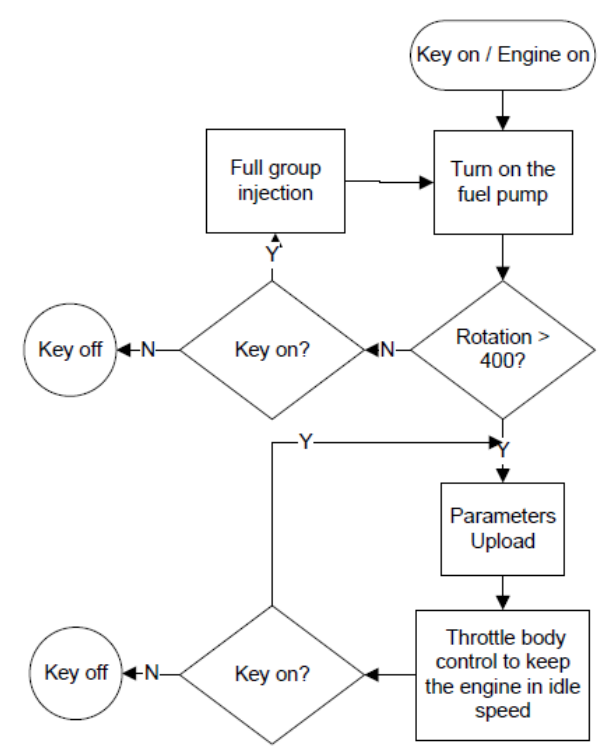

Figure 11. Second software developed (Management 2).

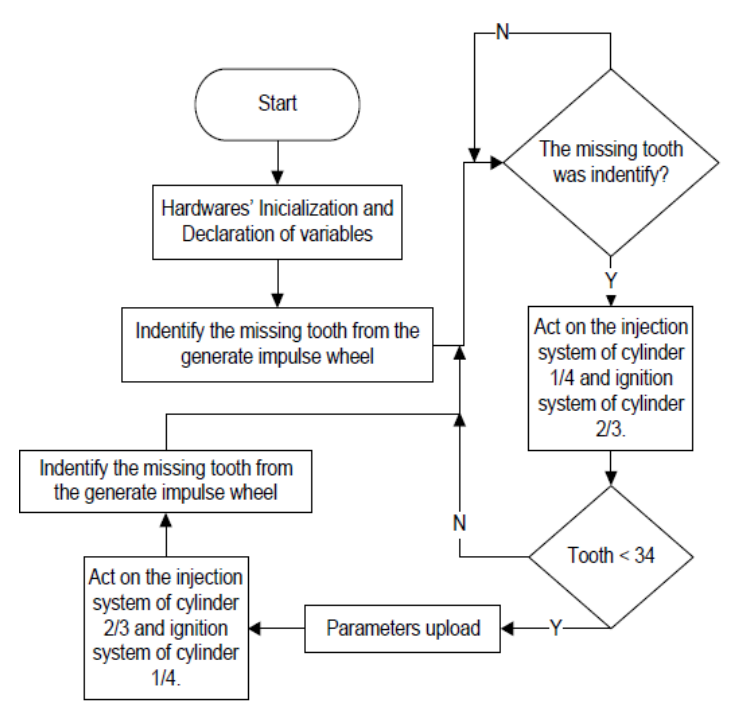

Figure 12. Third software developed (Synchronism). 


\section{ACKNOWLEDGMENT}

F. Delatore thanks for the financial support obtained from FUNADESP/IPADE of the Universidade Anhanguera/UNIABC in order to develop his researches on Didactic Strategies Focused on Engineering Course. F. S. Albaladejo, A. T. de C. and C. A. Morioka thanks to the Laboratory of Integrated Systems (LSI) from University of Sao Paulo (USP), to Centro Paula Souza and to General Motors for the all the help and the financial support obtained to develop this work.

\section{REFERENCES}

[1] Bereisa, Jonas. Applications of Microcomputers in Automotive Electronics. IEEE, 1983. 10 p J. Clerk Maxwell, A Treatise onElectricity and Magnetism, 3rd ed., vol. 2. Oxford: Clarendon, 1892, pp.68-73.

[2] Albaladejo, Felipe S.; Carvalho, Alexsander T.; Lagana, Armando A. M.; Morioka, Carlos A. Development of a mock-up for engineering education in automotive electronics. ICEE 2011

[3] Albaladejo, Felipe S.; Carvalho, Alexsander T.; Lagana, Armando A. M.; Morioka, Carlos A., Delatore, Fabio. Desenvolvimento de um "motor vivo" (mock-up) para ensino em eletrônica automotiva. COBENGE 2010.

[4] Albaladejo, Felipe S.; Carvalho, Alexsander T.; Lagana, Armando A. M.; Guedes, Marcos C.; Delatore, Fabio. A New Method for Learning Electronic Management of an Internal Combustion Engine with a Mockup. PAEE 2012.

[5] Flink, James, The Age of Automobile. Massachusetts, Halliday Lithograph, 1990. 440p.

[6] Milhor, Carlos E. Sistema de Desenvolvimento para Controle Eletrônico dos Motores de Combustão Interna Ciclo Otto. São
Carlos: Escola de Engenharia de São Carlos, Universidade de São Paulo, 2002. 86 p.

[7] Intruments, Texas. LM1949 Injector Driver Controller. Dallas: Texas Instruments, 2008. 15p.

[8] Silva, Cynthia Thamires da.; Pereira, Bruno Silva.; Lagana, Armando A. M.; Guedes, Marcos C.; Dias, Bruno Martin de Alcântara.; Albaladejo, Felipe Serafim. Didactic Sets for the Study of Automotive Electronics. PAEE 2012.

\section{AUTHORS}

F. S. Albaladejo is now with Volkswagen, working on Academy and training area (e-mail: serafim@lsi.usp.br).

A. T. Carvalho is now with FATEC Santo Andre as a director of the institution (e-mail: tresssino@gmail.com).

C. A. Morioka is now with FATEC Santo Andre as a coordinator of the Automotive Electronic Course (e-mail: prof-morioka@uol.com.br).

F. Leonardi is now with Centro Universitario da FEI as professor/researcher on Mechanical Engineering (email: fabrizio@fei.edu.br).

F. Delatore is now with FATEC Santo Andre and Universidade Anhanguera as a researcher on didactic strategies applied on the engineering courses (email: fdelatore@aedu.br ; fabio.delatore@fatec.sp.gov.br )

This work was supported in part by Laboratory of Integrated Systems (LSI) from University of Sao Paulo (USP). This article is an extended and modified version of a paper presented at the EDUCON2013 conference held at Technische Universität Berlin, Berlin, Germany from March 13-15, 2013. Received 15 May 2013. Published as resubmitted by the authors 21 May 2013. 